\title{
American Accreditation: Why Do It?
}

\author{
Deborah Prince* \\ Glion Institute of Higher Education, Switzerland
}

\begin{abstract}
A review of the history and purpose of accreditation followed by a brief case study of how a small specialist institution outside of the USA went through the process of becoming accredited. The changes needed inside the curriculum and inside the organization in order to make this significant organizational development are reviewed and discussed. The paper concludes with some discussion as to why a non-US based institution might decide to become accredited by an outside agency.
\end{abstract}

Keywords: NEASC, accreditation, organizational change, general education

\section{Background}

American accreditation systems are reputed to be the first in existence starting in 1885 with the New England Association of Schools and Colleges (NEASC). Although, the term accreditation was not used by NEASC until 1952 after others had coined the word (Brittingham, 2009). The idea of using external eyes to assure quality may not have been started by these voluntary bodies, but the American accreditation associations seem to have been the first to systematically agree and use processes and quality statements for educational institutions. Their systems are based on peer evaluations and, perhaps uniquely, they are not government agencies. US governmental control comes from the funding mechanisms which are linked to accreditation (Van Damme, 2002). Increasingly, there is tension between the US federal government questioning its role in accreditation and the degree to which American universities are delivering the promised learning outcomes for students (Brittingham, 2009).

Notwithstanding the tensions in the US system, other countries have sought to emulate the American model of accreditation, often mixing the American concept with local variations, which risks a loss of integrity with the system they seek to emulate (Van Damme, 2002). With the Bologna Declaration (in June 1999) the European Union (EU) embarked on a mission to harmonize its Higher Education systems which included bringing a uniformity of approach to Quality Assurance (QA) through accreditation systems with a distinct American style. The European Network for Quality Assurance in Higher Education (ENQA), whose current stated purpose is "to contribute significantly to the maintenance and enhancement of the quality of European higher education at a high level, and to act as a major driving force for the development of quality assurance across all the Bologna signatory countries" was initially meant to propose a harmonized system of QA for Europe. However, countries have divergent views on what constitutes quality and whether accreditation is desirable (Van Damme, 2002). Moreover, Europe is not yet unified despite the adoption of the Bergen 2005 ENQA's "Standards and Guidelines for Quality Assurance in the European Higher Education Area".

International standards for accreditation that would provide a method for assuring the standards of tertiary education's learning outcomes might be seen as desirable for an increasingly mobile workforce. However, even Europe has not yet managed to crack that "nut" despite the EU's strong desire for worker mobility. The unhindered movement of workers is enshrined in European law and, behind this, systems to encourage student mobility are

\footnotetext{
* Corresponding author (deborah.prince@glion.edu)
}

Suggested citation: Prince, D. (2012). American accreditation: Why do it? Higher Learning Research Communications, 2(3), 45-51. http://dx.doi.org/10.18870/hlrc.v2i3.71 
increasingly shaping the aspirations of the next generations of educated workers. But still the EU hasn't managed agreement on generally applicable accreditation standards, although many European countries have established national accreditation agencies. Hiding behind this problematic are deep rooted objections to the free movement of intellectuals, and thus commercial disadvantage dating from the late 14th Century. Mobility of scholars was a common feature of European university development until rulers took protective measures forbidding students to travel (Gürüz, 2011).

A second type of approach is for accreditors to break national boundaries themselves, where they actively seek to bring their national view of academic standards into different settings by changing their internal policies and practices. Some American accreditation associations have begun to do this (e.g. NEASC accredited the American College of Greece in 1981), initially by accrediting "American universities" outside of the US. Some associations now accredit institutions which deliver American Style education to international students. For example, NEASC now accredits Swiss based hospitality institutions, and the Western Association of Schools and Colleges (WASC) took a decision this year to allow accreditation of institutions outside the USA teaching in languages other than English. WASC's new policy states that it recognizes "that there are differences among nations and their institutions of higher education; the Commission seeks to establish procedures and policies that will ensure comparability and functional equivalence while adhering to WASC's fundamental values and standards" (Western Association of Schools, 2012).

These initiatives begin to challenge the concept that only governments control accreditation practices inside their national boundaries, as institutions seek ways to appeal and recruit international students. Van Damme's article (2002) reviewed the problematic associated with the globalization of education and the constraints, both social and political, which inhibit the development of an international framework.

\section{Problematic of American Accreditation}

First and foremost, the accreditation body needs to have a policy for accepting essentially "non-American" institutions into the association. In addition, even if the policy exists in practice, the members forming the decision making bodies have to actively support their own policies. The practice of "candidacy" gives the illusion that anyone can join the club, provided they meet the standards described in the candidacy documents. Underneath this lies a set of obvious and not so obvious pitfalls. Accreditation practices and the "standards of accreditation" are culturally bound. They assume a collective set of experiences, history, and understanding. Strommer and Brittingham (2004) elegantly summarized the nature of these cultural assumptions: the belief that people can improve themselves, the importance of choice, the forming of associations, the commitment to sharing of ideas and opinions, and pragmatism. These beliefs lead to a set of complex structures that are woven into the accreditation standards and expectations of accreditors. A naïve institution stepping into accreditation will find that they have to confront a series of hurdles which they might not have anticipated in advance. 
This paper provides a brief commentary of the experiences of a Swiss based institution moving into the world of American accreditation; the initial challenges and the ongoing operational issues.

The first and most important step the Institution took was to use an American consultant to guide it through the process. This was an important decision and provided the institution with immeasurable advantages. Firstly, NEASC was asked to suggest a consultant and, following their suggestions, appointed someone to guide the institution through the process. This demonstrated from the outset that the institution was serious about its commitment to accreditation: an important message. The individual appointed had good accreditation experience and had worked abroad. During the project, she lived and worked in Switzerland. She managed the accreditation process and event, but more importantly helped the institution understand the meaning of what was written in the accreditation standards and what adaptations were needed. She also wrote the report using terms that would be understood by the visiting teams and helped the institution understand what these meant. Initially, it was believed that the process would take a year, but 2.5 years later the institution was finally admitted into NEASC.

\section{Criteria and Into Action}

The criteria that had to be covered included, (a) making sure the institution had met the criteria, which are specific to non-US institutions, (b) having a public statement about being an American institution, (c) having a significant number of Americans or those with American education experience in the Governing board, faculty, and administration, (d) using English as the language of instruction, (e) giving American style degrees including General Education, and (f) having financial records that are American in style. These were in addition to the normal requirements for candidacy.

All these items were easy to write about, but they fundamentally revised the way the institution worked. Curriculum re-engineering was the first issue to face using credits (with defined contact hours and student learning hours), writing learning outcomes, and the concept that the syllabus is a contract between the institution and the student. This was a challenge for faculty teams. In addition, the number of years in the program, the calendar of the institution, and the number of credits in the degree were changed to match US expectations. Admission criteria were reviewed by looking at the age on entry and the years of secondary schooling. This is particularly challenging in an international setting where different countries have different secondary education systems. The admission team needed to become adept at unraveling and understanding educational systems around the world.

Introducing the concept of General Education and coming to an agreement about the purpose and nature of this program was probably the most difficult thing that had to be done. Most US institutions have General Education taught in the first year of the degree. The institution curriculum model required students to study the basics of hospitality in the first year, so that they could go into their first internship after 6 months of study. Therefore, a very different model for the institution's General Education program was chosen. It is a vehicle for the 
development of transferable skills (common skills) as well as having a curriculum broadening rationale. Considerable time was spent working with teams of visiting faculty to build a dynamic and interesting program delivered over the whole degree and focusing on the themes of international perspectives, culture and civilization, and environment and society. The General Education program has its own learning outcomes and over the last five years, it has slowly developed its own culture and acceptance in an institution that was traditionally highly vocational in nature. The "sales" work needed within the faculty was a significant task. In this curriculum area the accreditation teams have been persistently keen to see American faculty and leadership.

Generally, the accreditation requirement for a "significant" number of staff and faculty to be American or have experience of American Higher Education is a challenge. Visa and work permit restrictions make it very tricky and time consuming to employ Americans. When Americans who are already in situ are appointed, they are not always able to integrate and deliver what is expected. Among the many issues attached with American accreditation, this has proved to be the most demanding. However, there has been success in attracting and retaining staff and faculty with experience of American Higher Education. This means they have worked in American $\mathrm{HE}$ or that they have American degrees. What constitutes "significant" was a question where the accreditation agency was not specific: they said, "ideally some governors with American HE experience" and there are two in the institution's small governing board; they said, "some leadership roles" inside the institution and there have been a number of individuals who fulfilled this criterion. However, they often did not meet the standards of leadership the institution required and they have not stood the test of time. Currently, a few American faculty members are employed and a number of faculty members have American degrees.

American accreditation also expects there to be significant student services to support students in their personal and physical development. Fortunately, this was already a residential institution with infrastructures to support students in that context. However, the student services that were in place were not deemed sufficient in the first accreditation visit. At that time, the leadership of those services was not able to describe their function, coherence, and integrity effectively. What was missing was a leader who could speak English. This was a significant piece of learning for the institution. Not only did people need to provide the right type of services, but they also had to be articulate and be able to understand what the visiting accreditation teams were asking. Accreditation is about communication and the institution received strong criticism for its inability to discuss effectively what it was doing. As a result, the student services team was reorganized and put an English speaker into a leader role. It also added extra services for students and joined NASPA, the association for Student Affairs Administrators in Higher Education.

The institution needed to create a series of documents and new structures. It needed to write a "mission" which everyone agreed to: a collaborative exercise which took many months of writing and discussion. It had to create a strategic plan; another collaborative project involving all departments and over half the institution's staff and faculty in either workshops or committees where it was created, discussed, and agreed. It had to create a new system of governance, 
establishing a Governing Board and creating by-laws, which the owner could agree to. The board has to have over $50 \%$ independent members and for its association the chair must be independent. The governance standard is probably the most difficult to adhere to given the private for profit nature of the institution. Handing over the responsibility for decision making is quite alarming for any business. Gradually, student and faculty governors have been added to this Board as a way of responding to other aspects of the governance standard. Faculty must be consulted on matters which are pertinent to them, as should students. A faculty council was created, which is a formal vehicle for faculty to discuss their concerns with the management. The Academic Committee was created as the senior body decision making body, including students and faculty. It controls entry standard, program content, and other aspects of quality management. A faculty handbook was created to describe the standards of behavior, expectations of work performance, and the rights of faculty to share their views freely without fear of reprisal (Academic Freedom). Collegial responsibility for maintaining and improving teaching and learning was the philosophic stance guiding these last three.

Another important document created was the catalog. This is a detailed publication which describes the institution to students and other readers. The mission, calendar, programs, course details, faculty, and academic regulations are featured in the catalog, which is updated annually. An Institutional Manual was created, which brings together all the policies, regulations, intuitional governance structures, and senior job descriptions into one place. It requires another major exercise to maintain and update.

US accreditors are also very focused on "assessment". This can be summarized into a few simple words: plan what you are trying to do, collect data, evaluate success, and make changes based on this evaluation. This reflective data driven concept took a significant amount of energy to introduce into the institution. Leading the process, the academic teams began by introducing a range of review and evaluation policies and procedures. These were focused on student success, and teaching and learning. Introducing this kind of approach into other departments was much more problematic. It has taken over five years to move the institution's culture forward. Fortunately, this approach is congruent with other quality models and provides intellectual harmony for faculty teaching Quality Systems.

\section{Challenges}

The institution is not recognized by the Swiss government and this is why US accreditation was chosen. If the institution had been recognized and accredited locally there would have been another problem to face with American accreditation: riding two horses. Following two sets of accreditation standards creates tension and difficulties. These are only discovered after the work begins (predictably in curriculum design or entry standards or length of degree).

The real test for the institution comes during the accreditation process and visit. Given the need for good communication and for understanding the standards of accreditation, many staff and faculty were involved in writing the 100-page accreditation report. These teams spent nearly 18 months working: reading and interpreting the standards, collecting evidence, and 
reading the report as it developed. This creates understanding and a growing body of knowledge in the institution, which is key to a successful accreditation visit.

One of the most difficult problems encountered was the different terms used and having to make the report "American" enough for the readers to understand, but also comprehensible to staff and faculty. For example, induction in Switzerland means the time period when support is given to new students so that they become familiar with the institution; this is called orientation in the US. Similarly, the institution's Directeur Général is called President in a US institution. Nevertheless, all of the spelling and terms needed to be in the American form which could create some challenges... especially around time and dates, when the European convention is the 24 $\mathrm{hr}$ clock and day/month/year system and not the $12 \mathrm{~h}$ clock and month/day/year system prevalent in the US.

Finally, workshops and training events were held before the visit for staff, faculty, and students. A lot of attention was paid to make the visiting team welcome, showing them hospitality and anticipating their needs during the visit.

\section{Why Do It?}

So the question is: why consider American Accreditation? For this institution, there seemed to be no other place to go. The local government regulations at the time did not allow authorization of private institutions. Following the US accreditation option gave the institution a strong quality label and an internationally portable degree, designed for 12-year education systems, which suited the majority of the institution's student population.

The accreditation standards are designed to fit very diverse institutions and are worded in a very broad and interpretable way. This makes them applicable to most institutions regardless of where the institution resides, its size, its mission or its funding base.

From a student's perspective they gain an American accredited degree delivered in English, which Gürüz (2011) identified as a key characteristic sought by international students. Students from countries, whose educational systems are as yet not fully developed or internationalized, have high economic value when they return home. Laws linking immigration possibilities to study suggest that countries are seeking to retain these educated young people, thus reinforcing another opportunity for international students: geographic mobility.

Gürüz divided the world into "knowledge producers" and "knowledge consumers", and highlighted how important the OECD believes the mobility of labor is for future globalization of industry. However, until international standards for quality assurance and mutual recognition of professional qualifications are achieved, mobility has to be engineered by institutional decision making. The choice of American accreditation might provide a step in this direction. 


\section{References}

Brittingham, B. (2009). Accreditation in the United States: How did we get to where we are? New Directions for Higher Education, 2009(145),7-27. http://dx.doi.org/10.1002/he.331

Gürüz, K. (2011). Higher education and international student mobility in the global knowledge economy (Rev. 2nd ed.). Albany, NY: SUNY Press.

New England Association of Schools and Colleges Commission on Institutions of Higher Education. (2009, September). Requirements of affiliation for free-standing institutions abroad. Retrieved from https://cihe.neasc.org

Strommer, D., \& Brittingham, B. (2004, April). What is American about American higher education? How culture shapes universities abroad. The Official Journal of the Association of American International Colleges and Universities, 3, 3-17. Retrieved from http://www.aaicu.org/

Van Damme, D. (2002, May). Trends and models in international quality assurance and accreditation in higher education in relation to trade in educational services. Presented at the OCED/US Forum Trade in Educational Services, Washington, DC. Retrieved from http://www.oecd.org

Western Association of Schools and Colleges. (2012, February). A guide toward WASC accreditation for institutions incorporated outside the United States. Alameda, CA: WASC. Retrieved from http://www.wascsenior.org 